\title{
AUTORIA PARA PROPOSITURA DE AÇÃO POPULAR EM MATÉRIA AMBIENTAL: EXTENSÃO DA LEGITIMIDADE ÀS ORGANIZAÇÕES NÃO- GOVERNAMENTAIS
}

\author{
Rafaela Campos de Oliveira* \\ Juliana Campos de Oliveira**
}

Resumo: O desenvolvimento tecnológico ocorrido no mundo, desencadeado pela Revolução Industrial, ocasionou degradação ambiental em proporções preocupantes. Sob influência do paradigma antropocêntrico, não era dispensada devida atenção ao problema. Entretanto, com a evolução de pesquisas neste âmbito, foi se desenvolvendo o paradigma biocêntrico, que considerava o ambiente como um todo orgânico, no qual os seres humanos são componentes indissociáveis. A partir de então, Constituições de diversos Estados passaram a tutelar meio ambiente de forma mais eficaz, sendo incluído o acesso à justiça ambiental. Este artigo objetiva, deste modo, propor a inclusão das ONG's como legitimadas ativas para propor Ação Popular Ambiental.

Palavras-chave: Ação popular; Legitimidade ativa; ONG's; Efetividade; Tutela ambiental.

\section{LEGAL AUTHORSHIP FOR PROPOSITION OF POPULAR LEGAL ACTION IN ENVIRONMENTAL SUBJECT: EXTENSION FOR NON-GOVERNMENTAL ORGANIZATION'S LEGITIMACY}

\begin{abstract}
The technological-industrial development occurred in the world unleashed by the Industrial Revolution, causing environmental degradation in worrying proportions. At first, under the influence of the anthropocentric paradigm, the problem of environmental degradation was not given due attention. However, with the development of research in this area, the biocentric paradigm has been developed, which considered the environment as an organic whole in which humans are inseparable components. Since then, the Constitutions of several countries has begun to protect the environment more effectively, including access to environmental justice. This article proposes the inclusion of NGO's as active legitimates to Popular Environmental Action.
\end{abstract}

Keywords: Popular action; Active legitimacy; NGO'S; Effectiveness; Guardianship environmental.

\footnotetext{
*Doutoranda em Arquitetura e Urbanismo pelo Programa de Pós-Graduação em Arquitetura e Urbanismo da Universidade Federal da Bahia (PPGAU/UFBA); Mestre em Arquitetura e Urbanismo pelo Programa de PósGraduação em Arquitetura e Urbanismo da Universidade Federal da Bahia (PPGAU/UFBA); Especialista em Direito Ambiental pela Fundação Faculdade de Direito da Universidade Federal da Bahia (FFD/UFBA); Graduada em Direito pela Universidade Estadual da Paraíba (UEPB). E-mail: rafinhabmcampos@ yahoo.com.br ${ }^{* *}$ Doutoranda em Arquitetura e Urbanismo pelo Programa de Pós-Graduação em Arquitetura e Urbanismo da Universidade Federal da Bahia (PPGAU/UFBA); Mestre em Direito Público pelo Programa de Pós-Graduação em Direito da Universidade Federal da Bahia (PPGD/UFBA); Especialista em Direito do Estado pela Fundação Faculdade de Direito da Universidade Federal da Bahia (FFD/UFBA); Graduada em Direito pela Universidade Estadual da Paraíba (UEPB).E-mail: juli.camposo@gmail.com
} 


\section{Introdução}

No início do período de urbanização e crescimento industrial, em termos mundiais, sobretudo no limiar do século XIX, quando se estabeleceu o apogeu da Revolução Industrial, pouca ou nenhuma atenção era conferida à proteção ao meio ambiente natural.

Seguindo o paradigma antropocêntrico, o ser humano se considerava em patamar superior e independente da natureza.

Entretanto, o avanço nas pesquisas e a constatação de que a degradação do meio ambiente afeta diretamente aos seres vivos, incluindo os seres humanos, deu ensejo ao denominado paradigma biocêntrico. O desenvolvimento do paradigma biocêntrico, em detrimento do paradigma antropocêntrico, foi adquirindo mais força, o que proporcionou a compreensão da ideia de que o meio ambiente é um bem autônomo e que precisa ser tutelado não apenas em virtude da qualidade de vida do ser humano, mas também enquanto bem jurídico possuidor de autonomia e necessidades próprias.

Diante da atual conjuntura pandêmica, a questão ambiental passou a atravessar o cotidiano de qualquer cidadão ao redor do mundo. Por meio da experiência ora vivenciada, pode-se apreender que a relação homem-natureza, quando ultrapassa certos limites, certamente, desfavorece o bem ambiental mas, igualmente, pode trazer aos seres humanos situações inusitadas e fora de controle. Sob este prisma, o melhor a ser buscado para ambos, homem e natureza, é proteger esta relação e salvaguardar os direitos inerentes a cada uma das partes.

Com o progresso do paradigma biocêntrico, houve o surgimento de diversas legislações ambientais ao redor do mundo. A partir de então, as Constituições de diversos países, a exemplo do Brasil, passaram a tutelar o meio ambiente enquanto direito fundamental, e instrumentos processuais passaram a ser utilizados para sua proteção.

No Brasil, um desses instrumentos jurídicos processuais é a Ação Popular. Apesar de ser do entendimento geral que a Ação Popular tem como legitimados ativos os cidadãos, pretende-se, através deste artigo, defender que as Organizações não-governamentais (ONG's) que atuem enquanto defensoras do meio ambiente ecologicamente equilibrado possam ser legitimadas para propor Ação Popular. 
Utilizou-se, para tanto, de pesquisa bibliográfica de fontes primárias e secundárias, que retratam os cenários nacional e local existentes anteriormente à atual pandemia, que tem assolado as cidades ao redor do mundo.

\section{Proteção Ambiental: do Paradigma Antropocêntrico ao Paradigma Biocêntrico}

O crescimento econômico, o incremento dos estudos científicos que se estabeleceu, sobretudo, a partir da Revolução Industrial, no século XIX, trouxe inúmeros avanços tecnológicos, mas, em contrapartida, ocasionou também, explosão populacional no meio urbano, insalubridade nos ambientes de trabalho e moradia além de acentuada destruição ambiental. Neste período, foram tecidos os primeiros fios do capitalismo moderno.

\section{O capitalismo desorganizado se caracteriza pela pujança sem precedentes do mercado, que extravasando o domínio econômico, coloniza tanto o princípio do Estado como o da comunidade, neutralizando a capacidade de regulação nacional da economia, acentuando as diferenças entre o norte e o sul e comprometendo o equilíbrio da biosfera (GORDILHO, 2009b, p. 26).}

Imersos neste contexto, os cientistas possuíam um posicionamento antropocêntrico, em que o homem era o ator principal das relações sociais, sendo o meio ambiente natural considerado apenas como fornecedor de recursos para o progresso da humanidade. O ser humano era visto de forma apartada da natureza e em situação de superioridade.

Capra (2006, p. 25) defende que nesse período existia uma "ecologia rasa" e esclarece que "a ecologia rasa é antropocêntrica, ou centralizada no ser humano. Ela vê os seres humanos como situados acima ou fora na natureza, como a fonte de todos os valores, e atribui apenas um valor instrumental, ou de 'uso', à natureza'.

Com o passar dos anos, estudos passaram a demonstrar que os recursos naturais são limitados e que os seres humanos são parte integrante da natureza, dela dependendo sua sobrevivência. De um paradigma antropocêntrico, foram surgindo estudiosos defensores do paradigma biocêntrico, sobretudo na segunda metade do século XX, por volta da década de 70, quando ocorreu a Conferência das Nações Unidas sobre o Ambiente Humano, em Estocolmo, no ano de 1972.

Em outra obra, Gordilho (2009a, p. 92) salienta que "existe uma tendência mundial de superação do antropocentrismo clássico, e os elementos naturais cada vez mais têm sido 
objeto de consideração moral, pois muitas vezes são protegidos em detrimento dos interesses humanos imediatos".

O paradigma que está agora retrocedendo dominou a nossa cultura por várias centenas de anos, durante as quais modelou nossa moderna sociedade ocidental e influenciou significativamente o restante do mundo. Esse paradigma consiste em várias ideias e valores entrincheirados, entre os quais a visão do universo como um sistema mecânico composto de blocos de construção elementares, a visão do corpo humano como uma máquina, a visão da vida em sociedade como uma luta competitiva pela existência, a crença no progresso material ilimitado, a ser obtido por intermédio de crescimento econômico e tecnológico (CAPRA, 2006, p. 25).

O paradigma biocêntrico proporciona o estudo do meio ambiente natural como um todo orgânico que possui autonomia e interesses próprios. A preocupação com a proteção ambiental tornou-se fundamental, passando-se a pleitear a colaboração de todos na defesa dos problemas relativos à degradação ambiental.

O novo paradigma pode ser chamado de uma visão de mundo holística, que concebe o mundo como um todo integrado, e não como uma coleção de partes dissociadas. Pode também ser denominado visão ecológica, se o termo 'ecológica' for empregado num sentido muito mais amplo e mais profundo que o usual. A percepção ecológica profunda reconhece a interdependência fundamental de todos os fenômenos, e o fato de que, enquanto indivíduos e sociedades, estamos todos encaixados nos processos cíclicos da natureza (IDEM, IBIDEM).

Nesse processo evolutivo dos esforços relacionados à proteção do meio ambiente, as Constituições de diversos Estados passaram a inserir a tutela ambiental como direito fundamental, de caráter transindividual, consubstanciando-se em direito e dever de todos. Como exemplo, tem-se a Constituição de Portugal, de 1976, a Constituição da Espanha, de 1978 e a Constituição Brasileira, de 1988.

Olhando em volta, é seguro dizer que a constitucionalização do ambiente é uma irreversível tendência internacional, que coincide com o surgimento e consolidação do Direito Ambiental. [...] Nessa evolução acelerada, numa primeira onda de constitucionalização ambiental, sob a direta influência da Declaração de Estocolmo de 1972, vieram as novas Constituições dos países europeus que se libertavam de regimes ditatoriais, como a Grécia (1975), Portugal (1976) e Espanha (1978). Posteriormente, num segundo grupo, ainda em período fortemente marcado pelos padrões e linguagem de Estocolmo, foi a vez de países como o Brasil. Finalmente, após a Rio-92, outras Constituições foram promulgadas ou reformadas incorporando, expressamente, novas concepções, como a de desenvolvimento sustentável, biodiversidade e precaução. (...) a França, que em 2005 adotou sua Charte de I'environnement (BENJAMIN, 2007, p. 61-62). 
Mais recentemente, houve destaque para a visão biocêntrica da Constituição da República do Equador de 2008, que introduziu o conceito de "direitos da natureza". A Lei Maior equatoriana passou a ser vista como referência de legislação ambientalista, ao propor o novo Constitucionalismo Latino-Americano, fundado na sustentabilidade e democracia, pluralismo e reconhecimento da diversidade social, buscando uma nova institucionalidade inclusiva e participativa. Buscou a garantia do Estado de bem viver, superando a noção tradicional de Estado Social, surgida na segunda metade do século XX (PETTERS MELO; BURCKHART, 2018).

Relativamente ao Brasil, tem-se que a Constituição de 1988 recepcionou no caput do seu artigo 225 o direito fundamental ao meio ambiente ecologicamente equilibrado: “Art. 225. Todos têm direito ao meio ambiente ecologicamente equilibrado, bem de uso comum do povo e essencial à sadia qualidade de vida, impondo-se ao Poder Público e à coletividade o dever de defendê-lo e preservá-lo para as presentes e futuras gerações".

Diante da nova caracterização do direito ambiental como um bem autônomo e carente de tutela, alguns mecanismos de garantia de proteção foram adotados no Brasil, entre os quais a Ação Popular.

\section{Contexto Urbano e complexibilidade da Tutela Ambiental}

Nos dias atuais, os debates acerca da relação homem-natureza têm invadido os diversos campos de estudo e têm adquirido múltiplas nuances e especificidades. Nas cidades, a ocupação e ordenação do espaço passou a refletir novas dinâmicas, complexibilizando a relação homem-meio urbano.

No meio urbano, mais que sobreviver, passou-se a buscar melhores condições de vida e ampliação da longevidade. No século XIX, as aglomerações trouxeram consigo desenvolvimento, por meio do Capitalismo e Industrialização acelerados. Emergiram mazelas, epidemias, poluição, e, com estas, novas demandas quanti-qualitativas à satisfatória sobrevivência humana urbanizada.

O crescente processo de urbanização exigiu a adoção de medidas que visassem resguardar o bem-estar e a qualidade de vida das pessoas, em especial, daquelas que residem nos grandes centros urbanos, sobretudo no contexto de sociedade de risco ambiental, que passou a se apresentar. 
Com o aprofundamento científico, admitiu-se a necessidade de se dispensar maiores cuidados ao meio urbano, saneá-lo, tratá-lo, para melhoria da qualidade de vida humana. Suscitada esta questão, buscaram-se instrumentos que pudessem satisfazer as novas demandas urbanas, a princípio, com respaldo no esteticismo e no higienismo, trazendo, posteriormente, a sistematização da inserção das áreas verdes no planejamento das cidades. Emergiu a necessidade de preservação do meio natural e o reconhecimento dos benefícios trazidos à convivência dos cidadãos com este meio.

Com o passar do tempo, à evolução da abordagem desta nova relação homem-meio, adicionaram-se a regulamentação do meio urbano e organização do meio ambiente natural presente nas cidades, bem como, a normatização dos direitos e deveres do homem para com a natureza e o meio ambiente urbano.

Com maior ênfase a partir dos anos 1970, Encontros entre as Nações, com vistas à promoção das discussões ambientais, em âmbito global, foram realizados e tiveram grande repercussão, a exemplo da Conferência de Estocolmo (1972), na Suécia, e da Conferência da ONU Sobre Meio Ambiente e Desenvolvimento (ECO-92), ocorrida no Rio de Janeiro. Dessas discussões originaram-se relatórios, tratados, e cartas de princípios a serem seguidos pelos diversos países, na política de desenvolvimento e na política ambiental, tais como o Relatório Brundtland (1987) e a Agenda 21.

A legislação urbanístico-ambiental adotada em nosso país, especificamente, passou a compreender vasto elenco, que engloba desde as diretrizes federais, existentes na Constituição Federal, no Estatuto da Cidade (Lei Federal $n^{\circ}$ 10.257/01), às leis de âmbito municipal, abrangendo Planos Diretores, Lei de Ordenamento do Uso e Ocupação do Solo e leis específicas, tais como as que preveem instrumentos como o IPTU verde, o Plano Diretor de Arborização, entre outras.

No âmbito nacional, a Constituição Federal de 1988 (CF/88), trouxe consigo avanços urbanísticos e ambientais. Na seara ambiental, garantiu-se o acesso ao meio ambiente ecologicamente equilibrado para todos (artigo 225). No âmbito urbano, a Carta constitucional previu, em seu artigo 182, que a política de desenvolvimento urbano deveria visar o pleno desenvolvimento das funções sociais da cidade e garantir o bem-estar de seus habitantes.

Para dar cumprimento às diretrizes preconizadas pela Constituição promulgou-se o Estatuto da Cidade, Lei Federal $n^{\circ}$ 10.257, de 2001, prevendo, legalmente, a interseção entre os eixos ambiental e urbanístico. O Estatuto pretendeu auxiliar políticas locais de 
desenvolvimento urbano com diretrizes gerais que pudessem viabilizar o crescimento urbano compatibilizando-o, entre outros objetivos, com a sustentabilidade ambiental, social e econômica do município. O Estatuto previu o Plano Diretor e outros instrumentos de igual importância para a preservação da sadia qualidade de vida urbana, como o Estudo Prévio de Impacto Ambiental (EPIA) e o Estudo Prévio de Impacto de Vizinhança (EPIV).

Quando da promulgação deste arcabouço teórico legislativo, nas cidades, a urbanização de áreas naturais já se apresentava e deixava suas marcas sobre o tecido urbano, por um lado, por meio da inserção das Áreas Verdes, Parques e Jardins e, por outro, promovendo acentuada devastação de importante patrimônio ambiental.

A partir do momento de efervescência das discussões ambientais e emergência de vasto conteúdo normativo, as Áreas Verdes e Parques Urbanos passavam a ser legalmente tutelados como bens ambientais e equipamentos públicos urbanos.

Os desdobramentos referentes a estes equipamentos urbanos, entretanto, extrapolaram a mera questão legal que se atém por exemplo, ao preservacionismo ambiental e ao teor urbano-funcional das áreas verdes. A análise da inserção destes equipamentos nas cidades, faz sobressair o contexto de conflitos políticos e socioambientais em que estão imersos, interferindo diretamente no cotidiano dos cidadãos e nas condições do patrimônio ambiental urbano.

Isto porque, a cidade, palco da multiplicidade de agentes e de interesses conflitantes, expressa, via de regra, o resultado da prevalência de forças dominantes, tais como o mercado, a política, que, muitas vezes, não atendem às reais necessidades da urbe, dos cidadãos e do meio natural, podendo, inclusive, agir em desconformidade com a legislação vigente.

Paralelamente ao elenco de leis e diretrizes, incumbe aos gestores dos municípios, a função de tornar prática a previsão legal, intermediando os interesses em questão, de forma que a população citadina possa ser a principal beneficiária das políticas urbanas, sem, no entanto, prescindir da visão biocêntrica de preservação da natureza, propiciando o equilíbrio ambiental e a qualidade de vida de forma holística.

Entretanto, na prática, observa-se que há certa dificuldade, por parte da gestão pública, em efetivar os preceitos estabelecidos pelo arcabouço legal, e em estabelecer um ambiente urbano que satisfaça aos anseios por cidades que ofereçam melhor qualidade de vida aos seus habitantes e maior respeito à questão ambiental. 
A inadequada gestão das políticas públicas urbanas tem feito que as cidades venham expondo índices socioambientais negativos, que desqualificam o viver no meio urbano.

Presencia-se postura permissiva por parte do Poder Público das metrópoles brasileiras, sobretudo, frente aos movimentos especulativos do mercado imobiliário, que submete a organização do espaço urbano aos interesses e demandas do capital imobiliário, por tendenciar-se à apropriação do verde e dos remanescentes de natureza, pela prática e pelo discurso.

De acordo com os preceitos legais previstos na Constituição Federal, a natureza, por essência, se constitui em bem difuso, impassível de apropriação privada, devendo ser considerada patrimônio comum, cujos serviços ambientais e benesses deles advindas precisam ser compartilhadas pelo conjunto da sociedade.

Diante dos fatos, estabelece-se circunstância favorável aos atores da sociedade civil fazerem valer suas demandas autonomamente, por meio de instrumentos jurídicos como Ação Popular.

Adicionalmente, ante ao contexto ambientalmente desfavorável, faz-se mister a elaboração de novos instrumentos de ação destinados à propositura a partir da sociedade civil, para tutelar o bem ambiental. Ainda, faz-se imprescindível a adoção de novas abordagens de instrumentos jurídicos já existentes, que venham a ser tornados mais acessíveis e democráticos, passíveis de adaptação, de ampliação dos sujeitos ativos para sua propositura, com o intuito de expandir a sua efetividade e aplicação ante à tutela ambiental.

\section{A amplitude da questão Ambiental: Diversidade de Atores e Ação Popular como Instrumento de Tutela}

Em matéria ambiental é importante salientar que antes serem utilizados mecanismos que visem a reparação de danos, há uma preferência no sentido de se adotar medidas de prevenção e precaução. Neste sentido, Leite e Ayala admitem que "os meios judiciais são, de fato, o último recurso contra a ameaça e a degradação ambiental, pois antes destes os mecanismos de prevenção e precaução têm papel de destaque na política ambiental" (2002, p. 36).

Mas considerando-se que o risco de ocorrência de danos ambientais é constante, necessário se faz que existam instrumentos capazes da assegurar juridicamente que prejuízos ambientais sejam detectados e reparados na medida do possível. 
Mirra (1994, p. 18) esclarece que "realmente, por mais perfeitas que sejam as normas de controle e a sua aplicação, o dano ambiental ainda assim pode ocorrer, atado que está à inevitabilidade de acidentes".

No âmbito do Brasil tem-se que, de acordo com o caput do artigo 225, o direito ao meio ambiente ecologicamente equilibrado é direito de todos, sendo imposto não apenas ao Ministério Público, mas à toda coletividade o dever de proteção, visando tanto as presentes quanto as futuras gerações e demonstrando um caráter intergeracional.

A expressão "todos" trazida naquele dispositivo constitucional leva à interpretação de que deve haver, conforme explica Leite e Ayala, seguindo raciocínio adotado por Canotilho, uma “democracia ambiental". Neste sentido é indispensável que haja uma unidade entre cidadãos, Estado e meio ambiente.

Não há como negar que, para se discutir, impor condutas, buscar soluções e consensos que levem à proteção ambiental, é necessária a participação dos mais diversos atores (grupos de cidadãos, ONG's, cientistas, corporações industriais e muitos outros) e, por outro lado, um Estado democrático na perspectiva ambiental, detentor de um aparato legislativo apto a realizar essa tarefa. Trata-se, de fato, de o Estado passar a incentivar a emergência de um pluralismo jurídico comunitário participativo no viés ambiental, consubstanciado em modelo democrático, que privilegie a participação dos sujeitos sociais na regulamentação das instituições-chave da sociedade (LEITE e AYALA, 2002, p. 31).

É importante considerar ainda que, devido ao fato de que o meio ambiente não conhece fronteiras, a sua proteção adquire um caráter interterritorial. Atividades realizadas em um país podem prejudicar o meio ambiente natural de outro(s) país(es), gerando um dano ambiental em cadeia que pode trazer graves consequências para a integridade natural de todo o planeta.

\footnotetext{
No caso da proteção ao meio ambiente os obstáculos são ainda maiores, pois suas exigências dizem respeito à uma dimensão planetária, ou seja, demandam instrumentos em nível internacional ou intercomunitário e não isoladamente no interior do Estado de direito. Ao que parece, uma internacionalização das políticas de crescimento poderia ser um instrumento para deter a perda do patrimônio ambiental (IDEM, p. 23).
}

Sendo assim, é possível atribuir o dever de proteção ambiental a todos os indivíduos em âmbito mundial, sem distinção de nacionalidade ou território, tendo em vista a tutela do meio ambiente em nível internacional.

Em se tratando do acesso à justiça em matéria ambiental no Brasil, tem-se que além da Ação Civil Pública pode ser proposta a Ação Popular. 
A Constituição Federal de 1988 estabeleceu, em seu artigo 5a , inciso LXXIII que:

Qualquer cidadão é parte legítima para propor ação popular que vise a anular ato lesivo ao patrimônio público ou de entidade de que o Estado participe, à moralidade administrativa, ao meio ambiente e ao patrimônio histórico e cultural, ficando o autor, salvo comprovada má-fé, isento de custas judiciais e do ônus da sucumbência.

Este dispositivo constitucional permitiu que a Ação Popular pudesse ser proposta também em caso de ato lesivo ao meio ambiente. Entretanto, não houve uma modificação da Lei na 4.717, de 29 de junho de 1965, que regula a Ação Popular, no sentido de adequá-la a uma aplicação mais eficaz em matéria ambiental. Isto porque no âmbito do meio ambiente natural, é difícil mensurar a dimensão do dano, atribuir valor à natureza. Sendo assim, a inclusão das questões ambientais no âmbito de proteção da Ação Popular configurou um avanço, entretanto a sua utilização nos moldes da Lei $\mathrm{n}^{\mathrm{a}} 4.717 / 65$ limitou a tutela efetiva do meio ambiente em alguns casos. Um exemplo, é o âmbito restrito de legitimados ativos para propor esta ação.

De acordo com o artigo $1^{a}$ da Lei de Ação Popular, qualquer cidadão pode ser legitimado ativo para realizar sua proposição:

Qualquer cidadão será parte legítima para pleitear a anulação ou a declaração de nulidade de atos lesivos ao patrimônio da União, do Distrito Federal, dos Estados, dos Municípios, de entidades autárquicas, de sociedades de economia mista, de sociedades mútuas de seguro nas quais a União represente os segurados ausentes, de empresas públicas, de serviços sociais autônomos, de instituições ou fundações para cuja criação ou custeio o tesouro público haja concorrido ou concorra com mais de cinqüenta por cento do patrimônio ou da receita ânua, de empresas incorporadas ao patrimônio da União, do Distrito Federal, dos Estados e dos Municípios, e de quaisquer pessoas jurídicas ou entidades subvencionadas pelos cofres públicos.

Por cidadão entendem-se os indivíduos dotados de nacionalidade brasileira e de poderes políticos, uma vez que o $\S 3^{\text {a }}$ do artigo $1^{\text {a }}$, supracitado, esclarece que a prova de cidadania será feita através do título de eleitor, tal como por se verificar: “Art. $1^{\mathrm{a}}[\ldots], \S 3^{\mathrm{a}}$ : A prova da cidadania, para ingresso em juízo, será feita com o título eleitoral, ou com documento que a ele corresponda."

A Ação Popular é considerada o primeiro instrumento processual que possui claramente como escopo a proteção e defesa dos interesses da coletividade, porque apesar de ser impetrada por um particular, possui o objetivo de defender interesses difusos. 


\section{As Organizações Não-Governamentais como Legitimadas para Propor Ação Popular em Matéria Ambiental}

Atribuindo legitimidade ativa apenas aos cidadãos, a Lei da Ação Popular adquire caráter restritivo em matéria ambiental. É possível fazer esta afirmação devido a inúmeros fatores.

Um deles é que em geral, o polo passivo da ação é composto por grandes empresas ou até pelo próprio Estado. Nesse tipo de situação o cidadão, sozinho, se torna frágil, diante da grandeza econômica e de poder, do representante do polo passivo.

O particular ofendido não se apresenta, normalmente, em condições de assumir e desenvolver ação eficaz contra o agressor, quase sempre poderosos grupos econômicos, quando não o próprio Estado. Ademais, o dano causado a cada indivíduo normalmente será pequeno, dificilmente apreciável ou determinável. Assim, o particular fatalmente se sentirá desestimulado a empreender a defesa do ambiente, ou de bater às portas do Judiciário [...]. Tudo corre para desencorajá-lo: o vulto das despesas, a complexidade das questões, a carência de conhecimentos técnicos, a força política e econômica dos adversários. Outro fator é que, via de regra, os cidadãos não tem conhecimento, dimensão da sua responsabilidade em relação às questões ambientais. A falta de informação, de uma educação no âmbito da preservação do meio ambiente, torna a sociedade carente de atitudes individuais voltadas para proteção da natureza (MILARÉ,1993, p. 265).

Neste sentido, considera-se que seria necessária uma adequação da Ação Popular para garantir a tutela mais eficaz do meio ambiente.

Não é possível construir-se um Estado democrático do ambiente como Estado de direito sem a garantia do direito fundamental de amplo acesso à justiça e ao devido processo legal para as questões ambientais. Só com uma transformação profunda em várias áreas do direito, principalmente nos campos do direito civil e processo civil, de índole individualista, viabilizarse-á a tutela jurisdicional ambiental. O Direito do Ambiente tem uma dimensão horizontal e exige uma readaptação de outras áreas do saber jurídico, para se garantir o acesso adequado à justiça. A sociedade atual exige que os interesses ou direitos ambientais sejam palco de discussão na via judiciária, pois essa abertura resultará no exercício da cidadania e, como conseqüência, na conscientização ambiental (LEITE e AYALA, 2002, p. 36).

Uma modificação importante na Lei da Ação Popular seria a ampliação do rol de legitimados ativos, abrangendo além dos cidadãos de forma individualizada, os cidadãos de forma organizada, enquanto Organizações Não-Governamentais (ONG’s). Isto porque, via de 
regra, os integrantes de Organizações Não-Governamentais trabalham de forma direta na proteção dos interesses que defendem, neste caso, interesses de cunho ambiental. As ONG's ambientalistas são compostas por cidadãos que possuem maior nível de informação e consciência de sua responsabilidade perante a preservação do meio ambiente. São organizações que dispõem de respaldo técnico, científico e jurídico para desempenhar o papel a que se dedicam, também em âmbito jurídico.

Esta discussão remete à súmula 365 do Supremo Tribunal Federal que estabelece: “Pessoa jurídica não tem legitimidade para propor ação popular".

As Organizações Não-Governamentais são consideradas entidades com personalidade jurídica sem fins lucrativos, fazendo parte do chamado "terceiro setor", que de acordo com o que dispõe o Promotor de Justiça Tomás de Aquino Resende (2010, p. 1) configura-se como sendo

aquele que congrega as organizações que, embora prestem serviços públicos, produzam e comercializem bens e serviços, não são estatais, nem visam lucro financeiro com os empreendimentos efetivados, estando incluídas aqui, portanto, as associações, sociedades sem fins lucrativos e fundações.

Partindo-se deste pressuposto, as Organizações Não-Governamentais, ademais de possuírem personalidade jurídica, se configuram em pessoas jurídicas diferenciadas, por não visarem fins lucrativos.

Diante de tal ressalva, ainda que a Súmula 365 do Supremo Tribunal Federal estabeleça a impossibilidade de Pessoas Jurídicas proporem Ação Popular, defende-se a alegação de exceção que venha a autorizar às Organizações Não-Governamentais Ambientalistas a legitimação para propositura de Ação Popular em matéria ambiental.

É possível afirmar, deste modo, que se faz mister a modificação e atualização da Lei $\mathrm{n}^{\circ}$ 4.717/65 no sentido de ampliar o rol de legitimados ativos para propositura de Ação Popular em matéria ambiental.

De acordo com Oliveira Júnior, a súmula vinculante 365 do STF “perderá a eficácia se a norma que por ela foi interpretada vier a ser modificada ou alterada pelo Poder Legislativo" (2005, p. 1), possibilitando às Organizações Não-Governamentais a interposição de Ação Popular em matéria ambiental.

No Brasil, existem doutrinadores que defendem a ampliação da legitimidade ativa para propositura de Ação Popular, entre eles Celso Antônio Pacheco Fiorillo. 
É importante salientar que situação semelhante já é adotada na legislação de Portugal, a qual é considerada pioneira e atualíssima em termos de proteção ambiental. É fundamental que tais legislaçõos estrangeiras sejam inspiradoras de novas interpretações, com vistas à construção de sociedade brasileira mais educada e conscientizada ambientalmente, alinhada aos valores de proteção do bem ambiental natural, que venham refletir no paradigma jurídico, inclusive.

A experiência da class action dos Estados Unidos da América, a ação civil pública e a ação popular brasileiras, e a ação popular portuguesa são instrumentos mais atuais da tutela jurisdicional ambiental e têm incentivado os operadores jurídicos a discutir e refletir sobre as questões emergentes. A grande e, talvez, a maior dificuldade em construir um Estado ambiental é transformá-lo em um Estado de justiça ambiental (LEITE e AYALA, 2002, p. 37).

No que concerne à questão da justiça ambiental é importante destacar o pensamento de Cavedon e Vieira (2006) que considera outras variáveis, tais como a efetividade da utilização dos instrumentos jurídicos, bem como as dificuldades de acesso à justiça pelos autores habilitados a interpor as Ações.

A possibilidade formal de acesso à justiça em matéria ambiental através da disponibilização de instrumentos processuais de tutela coletiva não garante a sua efetiva utilização pelos titulares do bem ambiental. É preciso que os sujeitos de direitos ambientais tenham acesso à informação e estejam aptos a identificar as agressões ao meio ambiente como lesão a direito seu. Devem dispor de meios, materiais e informacionais, para fazer chegar à esfera jurídico-institucional os conflitos ambientais [...]. Verifica-se uma relação intrínseca entre justiça ambiental e acesso à justiça, já que os grupos que arcam com uma carga desproporcional de custos e riscos ambientais pelas suas condições socioeconômicas, racial, informacional e de poder, são também, por óbvio, os que enfrentam maiores barreiras de acesso (CAVEDON e VIEIRA, 2006, p. 13).

Posteriormente, refletindo acerca do acesso à justiça de forma democrática, afirmam os autores que:

Democratizar o acesso à justiça em matéria ambiental significa criar possibilidades para que os vitimados pela desigualdade e exclusão ambiental possam representar adequadamente o interesse ambiental lesado, com a garantia de ampla participação nos processos decisórios, dispondo de instrumental informacional para influir na conformação das decisões referentes aos conflitos jurídico-ambientais. Significa dar iguais possibilidades de inserir tais conflitos na esfera jurídico-institucional, o que pode se configurar em um meio eficaz de empoderamento dos grupos atingidos por situações de injustiça ambiental. Assim é que a garantia do amplo Acesso à justiça pode possibilitar a inserção dos excluídos ambientais, pela disponibilização de instrumentos e espaços democráticos de gestão 
ambiental e de decisão de conflitos, capazes de restabelecer a proporcionalidade na distribuição dos custos e benefícios ambientais (IDEM, p. 15).

Para completar esta discussão, mas longe de finalizá-la, vez que necessita de maiores debates e discussões, indispensável salientar as considerações abordadas por Canotilho (1995) sobre o tema da injustiça ambiental. Entende o autor, que a discriminação ambiental ou injustiça ambiental - entendida como qualquer decisão, prática administrativa ou atividade referente à tutela ambiental que venha a onerar, em termos discriminatórios, indivíduos, grupos ou comunidades em virtude de raça, situação econômica ou localização geográfica deve ser amplamente combatida por todos.

Entende-se, deste modo, que a ampliação dos legitimados ativos para propor a Ação Popular em defesa do meio ambiente garante o maior acesso à justiça, além de tornar a tutela do meio ambiente natural mais ampla.

\section{Conclusão}

Diante o exposto, conclui-se que por ser o meio ambiente natural um bem dotado de peculiaridades que o configuram como carente de tutela especial, necessita, por sua vez, que os instrumentos utilizados para sua proteção possuam características diferenciadas.

A proteção do meio ambiente é considerada transindividual e visa tutelar o meio ambiente enquanto bem jurídico autônomo e enquanto necessário à sobrevivência dos seres vivos da presente e das futuras gerações.

O que se objetiva, sobretudo, é a precaução e prevenção de danos ambientais. Mas ocorrendo tais danos, instrumentos processuais são disponibilizados para sua reparação. Entre eles, tem-se, no Brasil, a Ação Popular.

É notório, entretanto, que a Ação Popular, em matéria ambiental, sofre algumas limitações, devido ao fato de não ter sido adaptada às características particulares inerentes ao meio ambiente natural.

A mais importante dessas limitações é o âmbito restritivo dos legitimados ativos para propor a Ação Popular. Isto porque, apesar de ser direcionada a todos os cidadãos, no que concerne à proteção do meio ambiente, o que se tem é que os cidadãos, considerados de forma isolada, são frágeis e muitas vezes desconhecedores de seu papel perante as questões ambientais. 
Entende-se que possibilitando a entidades tais como as Organizações NãoGovernamentais Ambientalistas a propositura de Ação Popular em defesa do meio ambiente, o acesso à justiça seria mais eficaz, o que tornaria a tutela do meio ambiente natural mais ampla.

Defende-se ainda a flexibilização dos legitimados ativos para propor Ação Popular, uma vez que este instrumento processual é mais acessível, menos oneroso que a Ação Civil Pública.

Além disso, não há razão para a recusa na ampliação dos legitimados ativos proponentes da Ação Popular, uma vez que além de pretender trazer benefícios à tutela do meio ambiente, tal modificação não irá configurar em prejuízos para os demais bens tutelados por este instrumento.

\section{Referências}

ALFONSIN, Betânia de Moraes. A Política Urbana em disputa: desafios para a efetividade de novos instrumentos em uma perspectiva analítica de Direito Urbanístico Comparado (Brasil, Colômbia e Espanha). Tese (Doutorado em Planejamento Urbano e Regional). Programa de Pós-Graduação em Planejamento Urbano e Regional, Universidade Federal do Rio de Janeiro, Rio de Janeiro, 2008.

ALIER, Joan Martínez. O ecologismo dos pobres: conflitos ambientais e linguagens de valoração. Tradução: Maurício Waldman. 2. ed. São Paulo: Contexto, 2014.

BENJAMIN, Antônio Herman de Vasconcelos e. Direito constitucional ambiental brasileiro. In: CANOTILHO, José Joaquim Gomes; LEITE, José Rubens Morato (Org.). Direito constitucional ambiental brasileiro. São Paulo: Saraiva, 2007.

BRASIL. Constituição da República Federativa do Brasil de 1988. Disponível em: <http://www.presidenciadarepublica.gov.br>. Acesso em: 31 mar. 2020.

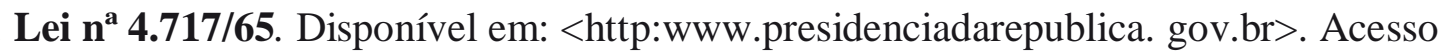
em: 31 mar. 2020.

CANOTILHO, Jose J. Gomes. Direito público do ambiente. Coimbra: Faculdade de Direito de Coimbra, 1995.

CAPRA, Fritjof. A teia da vida: uma nova compreensão científica dos sistemas vivos. Tradução: Newton Roberval Eichemberg. São Paulo: Cultrix, 2006.

CAVEDON, Fernanda de Salles; VIEIRA, Ricardo Stanziola. Acesso à justiça ambiental: um novo enfoque do acesso à justiça a partir da sua aproximação com a teoria da justiça ambiental. Disponível em: <http://www.conpedi.org/manaus〉. Acesso em: 5 abr. 2020. 
GORDILHO, Heron José de Santana. Abolicionismo animal. Salvador: Evolução, 2009a.

Direito ambiental pós-moderno. Salvador: Juruá, 2009b.

LEITE, José Rubens Morato; AYALA, Patryck de Araújo. Direito ambiental na sociedade de risco. Rio de Janeiro: Forense, 2002.

MILARÉ, Edis. Dano ambiental, prevenção, reparação e repressão. Antônio Herman V. Benjamin (Coord.). São Paulo: Editora Revista dos Tribunais, 1993.

MIRRA, Álvaro Luiz Valery. Fundamentos do direito ambiental no Brasil. Revista dos Tribunais, São Paulo, v. 83, n. 706, p. 7-29, ago. 1994.

OLIVEIRA JUNIOR, Roney. A solidez da súmula vinculante e a fragilidade da súmula impeditiva de recursos. Jus Navigandi, Teresina, ano 9, n. 575, 2 fev. 2005. Disponível em: <http://jus2.uol.com.br/doutrina/texto.asp?id=6271>. Acesso em: 4 abr. 2020.

PETTERS MELO, Milena; BURCKHART, Thiago. A Constituição equatoriana de 2008: uma nova concepção de Estado e pluralismo. Trayectorias Humanas Transcontinentales, 2018. Disponível em: <http://www.unilim.fr/trahs/902>. Acesso em: 21 set. 2020.

RESENDE, Tomás Aquino. Terceiro setor, ONG's e institutos. Disponível em: $<$ http://www.fundata.org.br/Artigos\%20\%20Cefeis/TERCEIRO\%20SETOR,\%20ongs.htm>. Acesso em: 6 abr. 2020. 